\title{
A STUDY OF THE FACTORS, INFLUENCING THE WORK OF THE RAILWAY STATION VANINO DVOST RAILWAY WITH LOCAL CARS Gusiatnikov N.A. ${ }^{1}$, Kakunina A.G. ${ }^{2}$ (Russian Federation) Email: Gusiatnikov326@scientifictext.ru
}

\author{
${ }^{I}$ Gusiatnikov Nikita Aleksandrovich - student; \\ ${ }^{2}$ Kakunina Anna Gennad'evna - Senior Lecturer, \\ DEPARTMENT OF ORGANIZATION OF TRANSPORTATION AND TRANSPORT SECURITY, \\ FAR EASTERN STATE TRANSPORT UNIVERSITY, KHABAROVSK
}

\begin{abstract}
West to the East, there is an increase volume of goods transported through the Vanino - Sovetskaya Gavan transport hub, in connection with the relevant question becomes efficient operation of the railway station Vanino, while increasing its processing capacity. The article gives a detailed analysis of the local car idle for items Vanino station identified "bottlenecks" According to the analysis suggested a number of measures to normalize the operation of the plant and reduce the time and monetary costs.

Keywords: station, port, local cars, a downtime local cars, grab unloading, processing capacity, exports, car dumper, port economic zone, free port of Vanino.

\section{ИССЛЕДОВАНИЕ ФАКТОРОВ, ВЛИЯЮЩИХ НА РАБОТУ ЖЕЛЕЗНОДОРОЖНОЙ СТАНЦИИ ВАНИНО ДВОСТ Ж.Д. С МЕСТНЫМИ ВАГОНАМИ \\ Гусятников Н.А. ${ }^{1}$, Какунина А.Г. ${ }^{2}$ (Российская Федерация)}

\author{
${ }^{1}$ Гусятников Никита Александрович - студент, \\ ${ }^{2}$ Какунина Анна Геннадьевна - стариий преподаватель, \\ кафедра организация перевозок и безопасности на транспорте, \\ Дальневосточный государственный университет путей сообщения, г. Хабаровск
}

\begin{abstract}
Аннотация: в последние годы, из-за смены ориентиров с Запада на Восток, наблюдается повышение объемов перевозимых грузов через Ванино - Советско-Гаванский транспортный узел, в связи с этим становится актуальным вопрос эффективной работы железнодорожной станции Ванино, при повышении её перерабатывающей способности. В статье проведен детальный анализ простоя местного вагона по элементам станциии Ванино, выявлены «узкие места». По результатам анализа предложен ряд мероприятий для нормализации работы станциии и уменьшения временных и денежных издержек.
\end{abstract}

Ключевые слова: станция, порт, местные вагоны, простой местных вагонов, грейферная выгрузка, перерабатывающая способность, экспорт, вагоноопрокидыватель, портовая экономическая зона, свободный порт Ванино.

ОАО «Ванинский морской торговый порт» имеет существенные стратегические, транспортные и географические преимущества перед портами Приморья, Сахалина и Камчатки, чьи акватории менее освоены. Ванинский порт - транспортный узел, связывающий воедино железнодорожный, морской и автомобильный пути. Через Ванино оставляются каботажные грузы на остров Сахалин, в другие северовосточные регионы России, экспортные грузы в большинство стран Азиатско-Тихоокеанского региона. Географическое расположение порта открывает ближайший выход к морю грузам, идущим с запада по Байкало-Амурской и Транссибирской железнодорожным магистралям [2].

На протяжении последних 5 лет работы железнодорожной станции Ванино происходит завышение такого показателя, как простой местного вагона, относительно нормативного параметра.

За 2016 год был произведен детальный анализ простоя местного вагона по элементам, представленный на рисунке 1. 
Средний простой одного вагона, ч

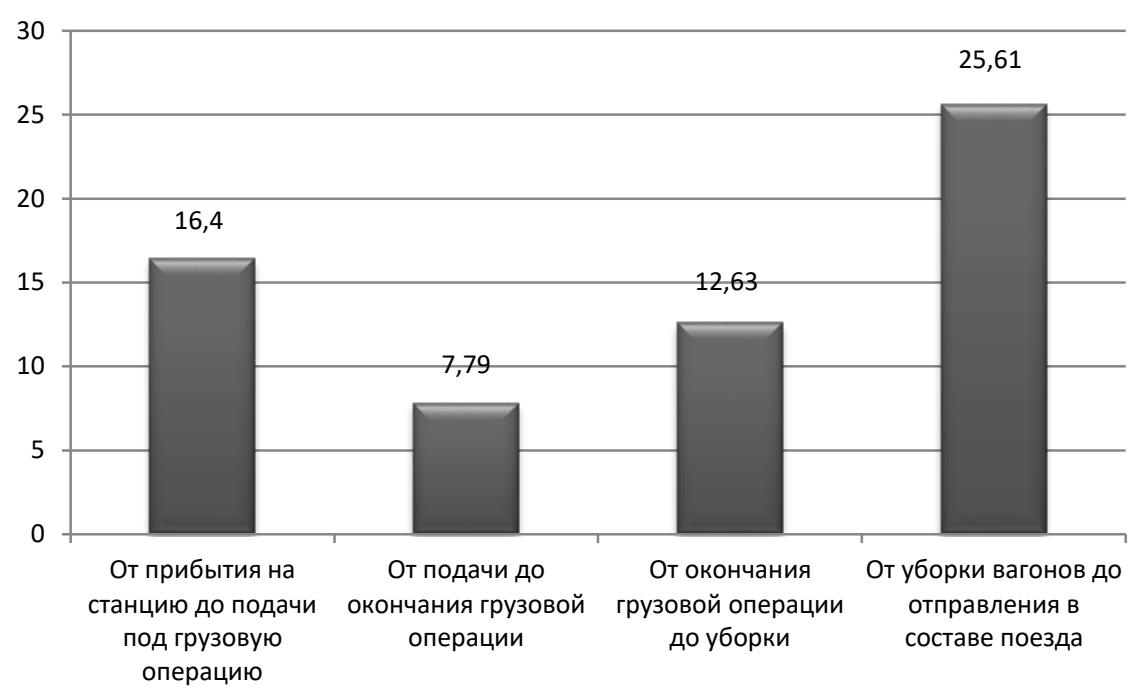

Рис. 1. Анализ простоя местного вагона

После анализа каждого элемента выявлено, что фактический простой на элементах 1 и 4 превышает нормативные показатели. Увеличение простоя местного вагона имеет разные причины. В связи с этим, с помощью диаграммы Исикавы (рис. 2), представлены различные причинно-следственные связи простоя вагонов. Диаграмма Исикавы дает возможность выявить ключевые параметры процессов, позволяющие установить причины проблем процесса или факторы, влияющие на возникновение проблемы.

К основным причинам завышения простоя местного вагона относительно нормативного показателя можно отнести:

- недостаточное количество устройств для разогрева;

- отправка промороженного угля грузоотправителем;

- несогласованный подвод поездов и судов;

- несовершенство планирования перевозок;

- низкий уровень организации ремонта поврежденных вагонов во время разгрузки;

- слабое стимулирование труда.

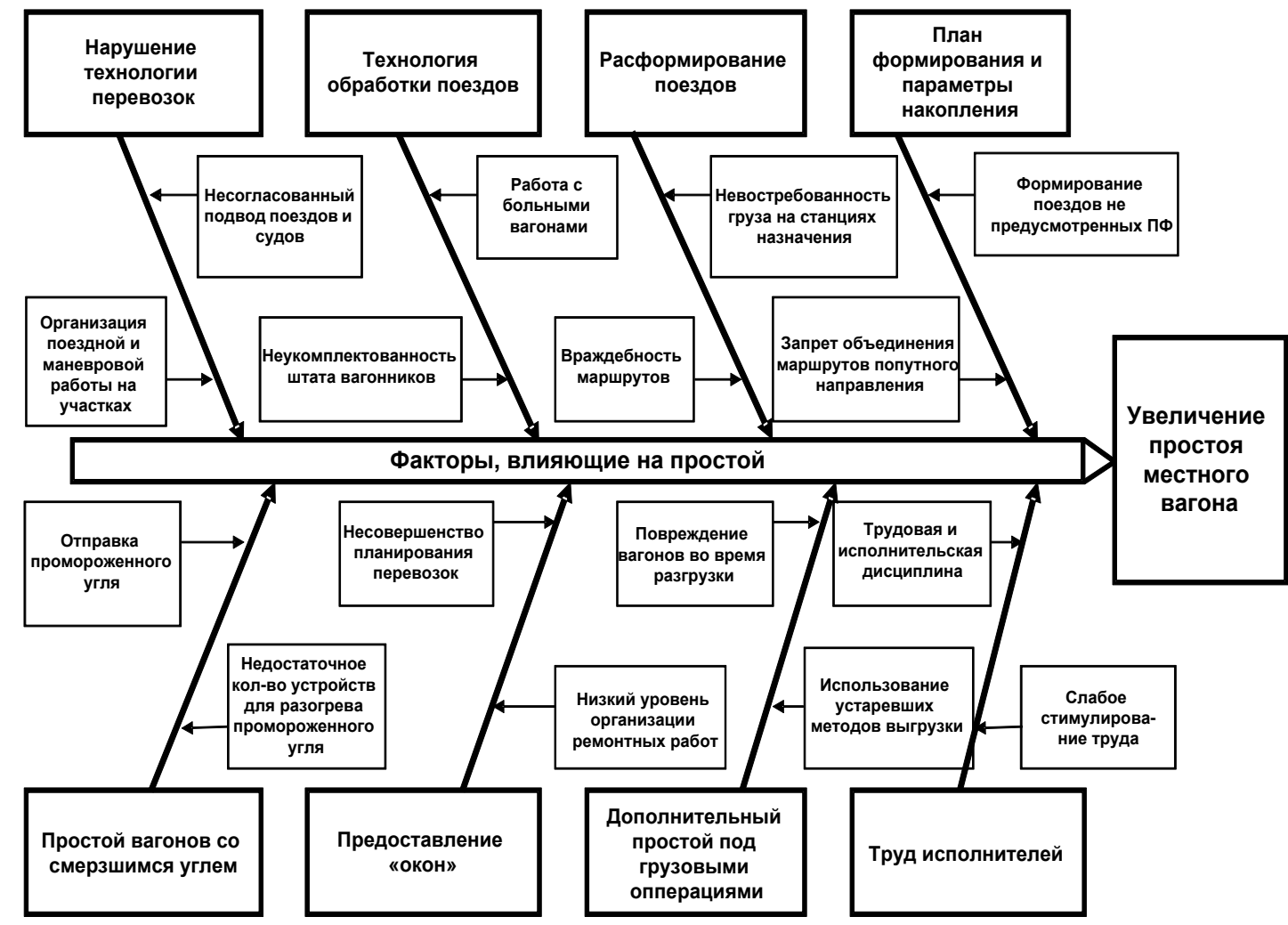




\section{Рис. 2. Основные причины завышения простоя местного вагона}

Для предотвращения дальнейшего увеличения простоя местного вагона и нормализации работы станции предлагается ввести ряд мероприятий:

- организовать согласованный подвод вагонов к станции, с целью сокращения простоя вагонов от прибытия на станцию до подачи под грузовую операцию;

- увеличить количество и длину существующих путей на станции и в порту;

- установка вагоноопрокидывателя с системой ленточных конвейеров;

- для оттаивания смерзшегося груза необходимо установить размораживающее устройство;

- оптимизировать очередность подач и уборок.

В настоящее время ВСТУ пользуется устаревшими технологиями, в частности, грейферной выгрузкой угля. Одним из мероприятий по увеличению мощностей выгрузочных устройств и уменьшения количества повреждений, получаемых вагонами, является установка на территории ВСТУ вагоноопрокидывателя с системой ленточных конвейеров.

Установка данного комплекса механизации позволит:

- снизить время на выгрузочные работы;

- уменьшить количество повреждений, получаемых вагонами при выгрузке; (Так, АО «Дальтрансуголь» при колоссальных объёмах выгрузки угля (19 млн тонн) за 2016 год повредило всего около 200 вагонов. При этом на предприятии налицо тенденция уменьшения повреждений из года в год. Стивидор использует вагоноопрокидыватель, отлаживает технологию работы с ним [4]).

- сократить время простоя местного вагона под грузовыми операциями и в ожидании уборки;

- автоматизировать процесс выгрузки;

- уменьшить негативные последствия от пыления угля.

Уменьшения длительности нахождения местных вагонов на станции, можно достичь путем оптимизации очередности подач и уборок вагонов.

Планирование и организация подач и уборок местных вагонов осуществляются следующим образом:

- для каждого грузового пункта устанавливаются нормы на все элементы простоя местных вагонов;

- для каждого грузового пункта рассчитывается число подач и уборок местных вагонов;

- с учетом условий работы станции и грузовых пунктов составляется график подач и уборок.

Оптимальное число подач и уборок определяется из условия обеспечения минимума суммарных эксплуатационных расходов, связанных с простоем вагонов в ожидании подачи, в ожидании уборки и затратой маневровых средств (локомотиво-часов).

Рациональная очередность подачи и уборки вагонов на грузовой фронт должна устанавливаться с учетом минимума общего суммарного простоя вагонов и затрат локомотиво-минут.

При правильном определении оптимального числа и рациональной очередности подач и уборок уменьшится простой местного вагона. Это приведет к минимизации издержек и денежных затрат за счет сокращения вагоно-часов и локомотиво-часов.

\section{Заключение.}

Стратегия развития угольной отрасли в России предполагает рост добычи и экспорта, что влечет за собой повышение объемов перевозимого угля в целом по стране. На сегодняшний день основное повышение происходит на Дальневосточном регионе, из-за смены экспортных ориентиров поставки угля от Европы к странам Азиатско-Тихоокеанского региона [1].

Ванино-Советско-Гаванский транспортный узел - одна из точек роста Хабаровского края. Полагаю, что в ближайшее время роль порта Ванино в экономики России будет возрастать. Порты Ванино и Советская Гавань обладают существенными преимуществами перед портами Приморья в отношении развития причальной линии. Они имеют до 900 гектаров свободной земельной территории и морских акваторий с глубинами до 22 метров, позволяющих строить причалы практически без проведения дноуглубительных работ, имеют прямой выход на две независимые железнодорожные магистрали Транссибирскую и Байкало-Амурскую (Северный широтный ход). При направлении транзитных и экспортных грузопотоков по Северному широтному ходу по международному транспортному коридору «Восток-Запад» через Ванинский транспортный узел из западных регионов России расстояние транспортировки сокращается более чем на 500 километров по сравнению с портами Приморья [3]. Через Ванино поставляются каботажные грузы на Сахалин, в другие северо-восточные регионы России и грузы в Азиатско-Тихоокеанский регион. Географическое расположение порта открывает ближайший выход к морю грузам, идущим с запада по Байкало-Амурской и Транссибирской магистралям [2].

На территории Хабаровского края создается портовая экономическая зона, объемы переработки грузов в которой значительно повлияют на общий грузопоток в ближайшие годы. Со строительством новых перевалочных мощностей ожидаются дополнительные перевозки в адрес Ванино-Совгаванского транспортно-промышленного узла. В этом году они должны достигнуть 30,4 млн тонн, а к 2020-му 
ожидается увеличение до 75,4 млн тонн. Активизировать работу планируют ООО «Сахатранс», ООО «Компания Ремсталь», ООО «Дальневосточный Ванинский порт» [5].

В последние годы, из-за смены ориентиров с Запада на Восток, наблюдается повышение объемов перевозимых грузов через Ванино - Советско-Гаванский транспортный узел, в связи с этим становится актуальным вопрос эффективной работы железнодорожной станции Ванино, при повышении её перерабатывающей способности. Решение данного вопроса позволит организовать нормальную работу станции и всего региона, предотвратить увеличение сроков доставки грузов и сократить временные и денежные издержки железной дороги, порта и клиентуры.

\section{Список литературы / References}

1. Анализ технологии взаимодействия железнодорожной станции Ванино и морского порта. // Молодежный научный форум: Технические и математические науки: электр. сб. ст. по материалам XLII студ. междунар. заочной науч.-практ. конф. М.: «МЦНО», 2017. № 2 (42). [Электронный ресурс]. Режим доступа: https://nauchforum.ru/archive/MNF_tech/2(42).pdf/ (дата обращения: 25.02.2017).

2. Ванинский порт: отвечая новым потребностям // Ванинский морской торговый порт. [Электронный pecypc]. Режим доступа: http://www.vaninoport.ru/wp-content/uploads/2016/11/vaninskiy-port.pdf/ (дата обращения: 01.03.2017).

3. Годовой отчет ОАО «Порт Ванино» за 2015 год // Ванинский морской торговый порт [Электронный pecypc]. Режим доступа: http:// www.vaninoport.ru/annual.html/ (дата обращения: 25.02.2017).

4. Клеймо против порчи // Газета «Гудок» Выпуск № 29 (26168) 21.02.2017. [Электронный ресурс]. Режим доступа: http://www.gudok.ru/newspaper/?ID=1365581\&archive=2017.02.21/ (дата обращения: 28.02.2017).

5. Макльгин Николай: «Нужно развивать пропускные способности на подходах к портам» // Газета «Гудок» [Электронный ресурс]. Режим доступа: http://www.gudok.ru/freighttrans/?ID=1346621/ (дата обращения: 01.03.2017). 